\title{
AN RFLP MARKER, CB75A, PREDICTS FOR PALMITIC ACID CONTENT ACROSS SELECTED OIL PALM GERMPLASM AND INTERSPECIFIC-HYBRIDS
}

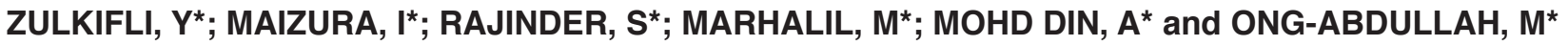

\begin{abstract}
Development of markers followed by construction of genetic linkage maps and quantitative trait locus (QTL) identification is a widely applied strategy towards marker assisted selection (MAS). In MPOB, researchers have reported that a restriction fragment length polymorphism (RFLP) marker, CB75A, generated from a $O x G$ genetic linkage map showed significant correlation with QTL for iodine value (IV) and fatty acid composition (FAC) in oil palm. This indicated a potential use of the marker to assist breeding to develop genotypes with more liquid oil. The objective of this study is to validate the CB75A marker across various independent populations to gauge its utility for oil palm breeding. Palms were selected based on their palmitic acid composition, and classified as low, intermediate and high. Validation was carried out using RFLP technique on 18 Madagascar germplasm samples from Trial 0.240 at MPOB Kluang, 20 hybrids from Trial 0.236 at MPOB UKM and 60 backcross 1 (BC1) from Trial 0.336 at MPOB Kluang. Three bands were observed and assigned as $A, B$ and $C$. The assay showed that the $A A$ genotype is associated with low palmitic acid. In addition, significant segregation can only be observed in interspecific hybrid backcross samples. This inferred that although CB75A can predict FAC content to some extent, additional markers are required for a more precise prediction.
\end{abstract}

Keywords: oil palm, palmitic acid, marker assisted selection.

Date received: 31 May 2018; Sent for revision: 4 Jun 2018; Received in final form: 31 July 2018; Accepted: 18 December 2018.

\section{INTRODUCTION}

The oil palm belongs to the genus Elaeis which can be distinguished into two species, Elaeis guineensis from Africa and Elaeis oleifera which is native to South America. The economic potential of E. guineensis is known and is currently one of the most important oil producing crops in the world. Although the oil yield from E. oleifera is lower, it does possess certain traits that are of interest to oil palm breeders. Elaeis

\footnotetext{
Malaysian Palm Oil Board,

6 Persiaran Institusi, Bandar Baru Bangi,

43650 Kajang, Selangor, Malaysia.

E-mail: zulkifly@mpob.gov.my
}

oleifera has a lower annual height increment rate in the range of $5-10 \mathrm{~cm}$ compared to commercial planting materials (E. guineensis) whereby the height increment ranges from 40 to $75 \mathrm{~cm}$ per year. In terms of oil quality, E. oleifera has higher levels of oleic and linoleic acids and its iodine value (IV) can reach up to 90 (Rajanaidu et al., 2000), contributing to a more liquid oil. Disease resistance, high carotene content and possible adaptation to dry seasons are other interesting characteristics of E. oleifera. The MPOB breeders travelled to eight countries in Central and South America to accumulate a collection of E. oleifera for research purposes (Zulkifli et al., 2012; Kushairi et al., 2017). Generally, direct exploitation of E. oleifera is not economically feasible due to its 
low oil yield. Thus, interspecific hybrid between E. oleifera $\times$ E. guineensis is generated to introgress genes of interest from E. oleifera into high yielding E. guineensis (Meunier and Hardon, 1976). The progenies obtained from both hybrids and backcrosses have demonstrated better oil quality with lower height increment than the commercial E. guineensis (Hardon, 1969; Mukesh and Tan, 1989; Rajanaidu et al., 1995; Mohd Din, 2000; Chin et al., 2003).

Marker assisted selection (MAS) techniques in hybrid-breeding programmes will help breeders increase unsaturated fatty acids levels in oil palm in a shorter time. Analysis of quantitative trait locus (QTL) for fatty acid composition (FAC) in an interspecific hybrid cross by Singh et al. (2009) revealed QTL associated with IV and FAC in oil palm. The study found a restriction fragment length polymorphism (RFLP) probe linked to the QTL associated with FAC. The RFLP probe was clones obtained from the cDNA libraries as described by Cheah and Rajinder (1998). The genotype revealed by the RFLP probe could differentiate palms with high and low levels of unsaturated oil. The study by Singh et al. (2009) used rigorous parameters for declaring linkage between the marker and trait concerned. However, it is important to verify and confirm that the marker-trait association extends beyond the mapping family used in the study. Hence, this study was conducted to validate the potential use of the RFLP probe (designated as CB75A) across different interspecific hybrids and oil palm germplasm materials.

\section{MATERIALS AND METHODS}

\section{Plant Materials}

A total of 60 interspecific hybrid backcross palms, 18 MPOB-Madagascar germplasm palms from MPOB Kluang Research Station, Johor, Malaysia and 20 hybrid samples from MPOB UKM Research Station, Selangor, Malaysia were utilised. The individual palms from the crosses and germplasm were classified into three groups based on their palmitic acid (C16:0) content: low (C16:0 $<33.0 \%)$, intermediate $(33.0 \%>\mathrm{C} 16: 0<38.0 \%)$ and high $(\mathrm{C} 16: 0>38.0 \%)$.

\section{RFLP Analysis with Selected Probe}

Validation was carried out using RFLP analysis. Spear leaves were harvested from each palm for DNA extraction. DNA extraction was carried out using the modified cetyl trimethylammonium bromide (CTAB) method (Dellaporta et al., 1983) from $4 \mathrm{~g}$ of fresh leaf tissue. Subsequently, the DNA was digested with a specific restriction enzyme,
DraI, and resolved by agarose gel electrophoresis. Following that, the DNA was transferred onto a membrane and pre-hybridised for $6 \mathrm{hr}$ in a buffer containing: 5X SSPE solution $(3 \mathrm{M} \mathrm{NaCl}$, $0.2 \mathrm{M}$ sodium phosphate, $20 \mathrm{mM}$ EDTA $\mathrm{pH}), 0.5 \%$ SDS, 5X Denhardt's solution $(0.1 \%$ Ficoll, $0.1 \%$ polyvinylpyrolidone, $0.1 \%$ albumin bovine fraction $\mathrm{V})$ and $100 \mu \mathrm{g} \mathrm{ml}^{-1}$ denatured herring sperm DNA. The pre-hybridisation buffer was removed and replaced with hybridisation solution consisting of 5X SSPE ( $3 \mathrm{M} \mathrm{NaCl}, 0.2 \mathrm{M}$ sodium phosphate, $20 \mathrm{mM}$ EDTA pH 8.0), 0.5\% SDS and $100 \mu \mathrm{g} \mathrm{ml}^{-1}$ denatured herring sperm DNA. Labelled probes were denatured by heating in boiling water for $10 \mathrm{~min}$ and then cooled down in ice water, before adding into the hybridisation buffer. The probe was labelled with $\alpha^{32} \mathrm{P}$-dCTP $\left(1-3 \times 10^{6} \mathrm{cpm} \mathrm{ml}^{-1}\right)$ and hybridisation was carried out overnight at $65^{\circ} \mathrm{C}$. Hybridised membranes were washed twice in $2 X$ SSC ( $0.3 \mathrm{M} \mathrm{NaCl}, 30 \mathrm{mM}$ trisodium citrate, $\mathrm{pH} 7)$, $0.1 \% \mathrm{SDS}$ at $65^{\circ} \mathrm{C}$ for $15 \mathrm{~min}$ each time, followed by once in 1 X SSC $(0.15 \mathrm{M} \mathrm{NaCl}, 15 \mathrm{mM}$ trisodium citrate, $\mathrm{pH} 7), 0.1 \% \mathrm{SDS}$ at $65^{\circ} \mathrm{C}$ for $15 \mathrm{~min}$. The membranes were then autoradiographed onto X-ray film at $-80^{\circ} \mathrm{C}$ with intensifying screen for 7 to 10 days. The X-ray films were developed using $0.22 \mathrm{X}$ Kodak's GBX developer for $5 \mathrm{~min}$, rinsed in distilled water, followed by a final wash with $0.2 \mathrm{X}$ Kodak's GBX fixer for $5 \mathrm{~min}$.

\section{Duncan Analysis Using SAS}

Using SAS version 9.3 software, Duncan analysis was carried out to determine the association of specific genotypes with C16:0 content. Samples were separated based on their allelic combinations for the CB75A profile. The C16:0 contents were averaged for each allelic combination for comparison purposes.

\section{RESULTS}

\section{CB75A RFLP Profile}

The RFLP probe CB75A was previously found to be able to differentiate palms with low and high unsaturated oil in an interspecific hybrid breeding population (Singh et al., 2009). This study aimed to determine the usefulness of the probe in a larger population of different genetic backgrounds. As the success in the use of a MAS/QTL linkage map is determined by the tight linkages between markers and QTL, validation of the CB75A marker is an important step to verify the efficiency of the marker associated with the trait of interest. Three distinct populations were utilised, i.e. an interspecific hybrid population, a backcross one hybrid population and germplasm from Madagascar, basically of the 
E. guineensis species. In this study, samples were selected based on their palmitic acid composition, classified as low, intermediate and high. Palms from the three populations were hybridised with CB75A and an example of the RFLP pattern observed is shown in Figures 1 and 2.

In the populations analysed, three segregating alleles were generally observed and classified as A, B and $C$. Each palm was either homozygous for one of the alleles or heterozygous for any two of the alleles. The segregation pattern observed and percentage of occurrence of the different allelic combinations are shown in Tables 1 to 3 .

Of the 60 backcross samples, 20 samples were classified as low $\mathrm{C} 16: 0$ and the majority displayed the $\mathrm{AA}(95 \%)$ and $\mathrm{AB}(5 \%)$ genotypes. The $\mathrm{C}$ allele was not detected in any of the samples with low C16:0. In intermediate C16:0 backcross samples, $47 \%$ of the palms had AA, 37\% AB, 11\% AC and 5\% had $\mathrm{BB}$ genotypes. There were 20 backcross samples classified with high palmitic acid content. Five percent of these samples showed AA genotype, 15\% had $\mathrm{AB}$ and $40 \%$ had AC genotype. An additional $15 \%, 20 \%$ and $5 \%$ of the high palmitic samples had $\mathrm{BB}, \mathrm{BC}$ and $\mathrm{CC}$ genotypes, respectively.

In hybrids, their range of palmitic acid content was narrower and many palms fell in the low and high C16:0 groups. Only three samples had C16:0 below $33.0 \%$ and all three displayed BB genotypes. For intermediate C16:0 samples, $83 \%$ had BB genotypes and $17 \%$ revealed CC genotypes. In the high $\mathrm{C} 16: 0$ group, BB and CC genotypes were observed in $60 \%$ and $40 \%$ of the samples, respectively. Meanwhile, all 18 MPOB-Madagascar samples exhibited high levels of C16:0 but all possessed only the CC genotype.

\section{Association of Specific Genotypes with C16:0 Content}

Samples were also separated based on their allelic combinations for the CB75A profile. Palmitic acid values were averaged for each allelic combination for comparison purposes (Table 4).

Generally, the average palmitic acid content was significantly different for selected genotypes, especially the AA and CC homozygous genotypes, which represented the extremes of low and high C16:0 content, respectively. Palmitic acid content displayed by heterozygous genotypes with $\mathrm{A}$, $\mathrm{B}, \mathrm{C}$ combinations as well as BB homozygous genotype were not different from one another. These genotypes were grouped in the intermediate C16:0.

\section{DISCUSSION}

Marker-trait association needs to be validated before large-scale MAS applications can be implemented. Several factors may contribute to the inconsistencies observed in marker/QTL mapping
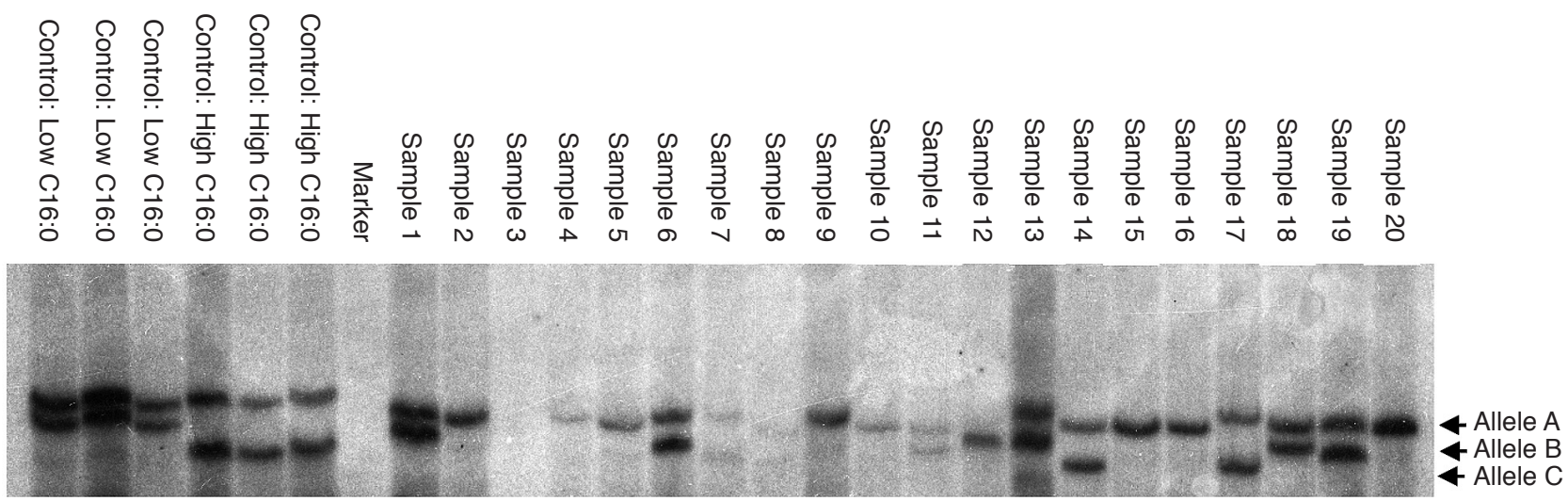

Figure 1. Autoradiogram result obtained for 20 backcross samples with palmitic acid content ranging from $33.1 \%-38.0 \%$.
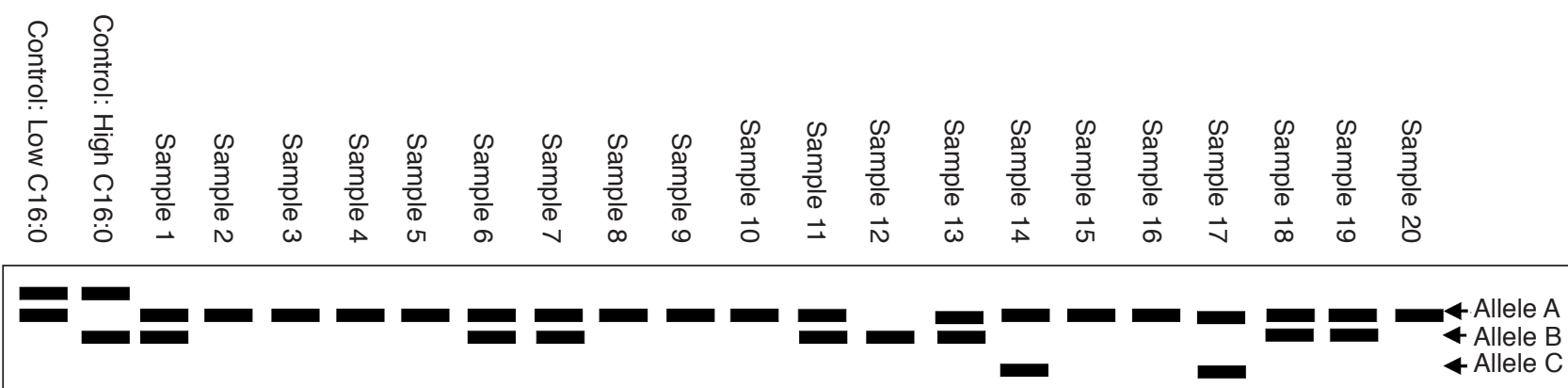

Figure 2. Illustration of autoradiogram result obtained for 20 backcross samples with palmitic acid content ranging from $33.1 \%-38.0 \%$. 
TABLE 1. THE PERCENTAGE OF OBSERVED GENOTYPES USING PROBE CB75A ON 60 BACKCROSS MATERIALS

(20 samples per each group containing different level of $\mathrm{C} 16: 0$ )

\begin{tabular}{cccc}
\hline Genotype & $\mathbf{C 1 6 : 0 < 3 3 . 0}$ & $\mathbf{3 3 . 0} \mathbf{C} \mathbf{1 6 : 0 < 3 8 . 0}$ & $\mathbf{C 1 6 : 0 > 3 8 . 0}$ \\
\hline AA & $95 \%(19)$ & $47 \%(10)$ & $5 \%(1)$ \\
AB & $5 \%(1)$ & $37 \%(7)$ & $15 \%(3)$ \\
AC & - & $11 \%(2)$ & $40 \%(8)$ \\
BB & - & $5 \%(1)$ & $15 \%(3)$ \\
BC & - & - & $20 \%(4)$ \\
CC & - & - & $5 \%(1)$ \\
\hline Total No. of samples & 20 & 20 & 20 \\
\hline
\end{tabular}

Note: No. of samples indicated within parentheses.

TABLE 2. THE PERCENTAGE OF OBSERVED GENOTYPES USING PROBE CB75A ON 20 HYBRID MATERIALS (C16:0 levels ranging from $30.9 \%$ to $47.4 \%$ )

\begin{tabular}{cccc}
\hline Genotype & C16:0 $<33.0$ & $33.0>$ C16:0 $<38.0$ & C16:0 $>38.0$ \\
\hline BB & $100 \%(3)$ & $83 \%(10)$ & $60 \%(3)$ \\
CC & - & $17 \%(2)$ & $40 \%(2)$ \\
\hline Total No. of samples & 3 & 12 & 5
\end{tabular}

Note: No. of samples indicated within parentheses.

TABLE 3. THE PERCENTAGE OF OBSERVED GENOTYPES USING PROBE CB75A ON 18 MADAGASCAR GERMPLASM (C16:0 levels ranging from $41.9 \%$ to $54.5 \%$ )

\begin{tabular}{cccc}
\hline Genotype & $\mathrm{C} 16: 0<33.0$ & $33.0>\mathrm{C} 16: 0<38.0$ & $\mathbf{C 1 6 : 0}>\mathbf{3 8 . 0}$ \\
\hline CC & - & - & $100 \%(18)$ \\
\hline Total No. of samples & 0 & 0 & 18 \\
\hline
\end{tabular}

Note: No. of samples indicated within parentheses.

TABLE 4. CORRELATION BETWEEN GENOTYPES LINKED TO PALMITIC ACID USING DUNCAN TEST

\begin{tabular}{cc}
\hline Genotype & Mean \pm S.E. \\
\hline AA & $32.717 \pm 0.54 \mathrm{c}$ \\
AB & $36.282 \pm 0.87 \mathrm{~b}$ \\
AC & $39.050 \pm 0.41 \mathrm{~b}$ \\
BB & $36.842 \pm 0.88 \mathrm{~b}$ \\
BC & $38.925 \pm 0.62 \mathrm{~b}$ \\
CC & $44.991 \pm 1.13 \mathrm{a}$ \\
\hline
\end{tabular}

Note: Mean \pm S.E. bearing the same alphabet are not significantly different from one another (at $\mathrm{P}<0.05)$.

which include differences in genetic background, epistasis effects and inaccurate phenotyping of the mapping population, which can reduce the power and precision of the marker/QTL detected. Cross validation in independent populations is necessary to obtain unbiased estimates of marker/QTL effects. The interspecific hybrid breeding programmes in Malaysia hopes to improve oil palm's potential to compete in the liquid oil market sector (Zulkifli et al., 2017). To realise this target, the main objective of the breeding programme at MPOB is to breed for lines that produce oil with oleic acid content of more than $60 \%$, palmitic acid content below 25\% and IV values above 72, without affecting the yield (Rajanaidu et al., 1983).
The results of this study indicated that although certain allelic combinations of CB75A is able to predict for FAC (measured in terms of C16:0) to some extent, it is by no means a perfect marker. Thus, there is still a need to find a marker more closely linked to FAC. Furthermore, a single QTL may not explain all the variations in FAC, as demonstrated in other oil crops (Ecke et al., 1995; Hu et al., 2006; Akond et al., 2012). However, the results do indicate that CB75A does point to the region in the oil palm chromosome that significantly influences FAC levels. The actual gene responsible for FAC may still be a distance away from the CB75A marker, thus chromosome recombination between marker and the gene may still occur. Segregation of the three alleles are only observed in backcross samples but not in hybrid and germplasm samples.

Although the marker CB75A is a useful indicator for FAC profile, its utility as a RFLP probe has limitations due to the large quantities $(1-10 \mu \mathrm{g})$ of purified, high molecular weight DNA required. The requirement of radioactive isotope also makes the analysis relatively expensive and hazardous. The assay is time-consuming and laborious which is highly inconvenient if additional crosses have to be validated or for routine use. Nevertheless, this study did reveal that this probe is a good candidate 
to identify interspecific hybrid backcross palms with favourable allelic combinations for lower C16:0 content. Such palms would be ideal for establishing the next generation of interspecific hybrid backcross palms. It would be more convenient if the probe is converted to a simple polymerase chain reaction (PCR)-based assay. However, additional PCR or sequence-based markers may be required to predict the trait with higher accuracy. Currently, there are two popular forms of sequence-based markers, simple sequence repeats (SSR), also known as microsatellites and single nucleotide polymorphisms (SNP), which now dominate the applications in modern plant genetic analyses. These two marker systems are more reliable, easy to handle, are present abundantly in the genome with high levels of polymorphism and are amenable for high-throughput detection formats and platforms. For this reason, MPOB researchers are aggressively pursuing the application of both marker systems in mapping and QTL studies with the aim of obtaining a more accurate marker-trait association (Low et al., 2017).

\section{CONCLUSION}

In summary, the RFLP marker, CB75A, can essentially be used as an indicator of the level of unsaturation in the oil especially from interspecific hybrids. This can assist breeders to manipulate the FAC in oil palm through molecular breeding. The probe also provides early clues of the region on the genome influencing FAC in oil palm. Furthermore, saturation of the region with additional PCR-based molecular markers such as SSR and SNP, will likely reveal markers more tightly linked to the trait, which can then be used with increased confidence in breeding programmes.

\section{ACKNOWLEDGEMENT}

We wish to thank the Director-General of MPOB for permission to publish this research finding.

\section{REFERENCES}

Akond, M G; Bobby, R; Richard, B; Stella, K K; Khalid, M and Abdel Majid, K (2012). Quantitative trait loci associated with moisture, protein, and oil content in soybean [Glycine max (L.) Merr.]. J. Agricultural Science, 4 (11): 16-25.

Cheah, S C and Rajinder, S (1998). Gene expression during flower development in the oil palm. Project Completion Report No. 0057/98. MPOB, Bangi.
Chin, C W; Suhaimi, S; Nasaruddin, M M and Ng, W J (2003). Selection of elite ortets from interspecific hybrids and backcrosses. Proc. of the PIPOC 2003 International Palm Oil Conference. MPOB, Bangi. p. 36-50.

Dellaporta, S L; Woods, J and Hicks, J B (1983). A plant DNA mini preparation: Version II. Plant Mol. Biol., 1: 19-21.

Ecke, W; Uzunova, M and Weissleder, K (1995). Mapping the genome of rapeseed (Brassica Napus L). 2. Localization of genes-controlling erucic-acid synthesis and seed oil content. Theoretical and Applied Genetics, 91: 972-977.

Hardon, J J (1969). Interspecific hybrids in the genus Elaeis. II. Vegetative growth and yield of F1 hybrids E. guineensis x E. oleifera. Euphytica, 18: 380.

$\mathrm{Hu}, \mathrm{X}$ Y; Sullivan-Gilbert, M; Gupta, M and Thompson, S A (2006). Mapping of the loci controlling oleic and linolenic acid contents and development of FAD2 and FAD3 allele-specific markers in canola (Brassica napus L.). Theoretical and Applied Genetics, 113: 497-507.

Kushairi, A; Singh, R and Ong-Abdullah, M (2017). The oil palm industry in Malaysia: Thriving with transformative technologies. J. Oil Palm Res. Vol. 29: 431-439.

Low, E T L; Jayanthi, N; Chan, K L; Nik Shazana, N M S D; Mohd Amin, A H; Rozana, R; Norazah, A; Nadzirah, A; Angel, L P L; Ong-Abdullah, M; Singh, R; Mohamad Arif, A M; Ravigadevi, S; Ahmad Parveez, G K and Kushairi, A (2017). The oil palm genome revolution. J. Oil Palm Res. Vol. 29: 456-468.

Meunier, J and Hardon, J J (1976). Interspecific hybrids between Elaeis guineensis and Elaeis oleifera. Oil Palm Research. Elsevier, Amsterdam. p. 127-138.

Mohd Din, A (2000). Genetic Variation for Yield, Bunch Component and Vegetative Traits in Oil Palm (Elaeis oleifera) and Interspecific Hybrids. Ph.D thesis, Universiti Kebangsaan Malaysia, Bangi, Selangor, Malaysia.

Mukesh, S and Tan, Y P (1989). Performance of the E. oleifera $\times$ E. guineensis (OG) hybrids and their backcrosses. Proc. of the 1989 PORIM International Palm Oil Congress. MPOB, Bangi. p. 40-43.

Rajanaidu, N; Rao, V and Tan, B K (1983). Analysis of fatty acids composition (FAC) in Elaeis guineensis, Elaeis oleifera, their hybrids and its implications in breeding. PORIM Bulletin No. 7: 9-20. 
Rajanaidu, N; Chin, C W and Jalani, B S (1995). Performance of Elaeis oleifera (Surinam) $\mathrm{x} E$. guineensis hybrids. Proc. of the Seminar on Worldwide Performance of DxP Oil Palm Planting Materials, Clones and Interspecific Hybrids. Barranquilla, Colombia. p. 108-113.

Rajanaidu, N; Kushairi, A; Rafii, M; Mohd Din, A; Maizura, I and Jalani, B S (2000). Oil palm breeding and genetic resources. Advances in Oil Palm Research (Yusof Basiron; Jalani, B S and Chan, K W eds.). Volume 1. MPOB, Bangi. p. 171-237.

Singh, R; Soon, G T; Jothi, M P; Rahimah, A R; Leslie, C L O; Eng-Ti, L L; Mukesh, S; Johannes, J and Suan-
Choo, C (2009). Mapping quantitative trait loci (QTLs) for fatty acid composition in an interspecific cross of oil palm. BMC Plant Biology, 9: 114.

Zulkifli, Y; Norziha, A; Naqiuddin, M H; Fadila, A M; Nor Azwani, A B; Suzana, M; Samsul, K R; OngAbdullah, M; Singh, R; Ahmad Parveez, G K and Kushairi, A (2017). Designing the oil palm of the future. J. Oil Palm Res. Vol. 29: 440-455.

Zulkifli, Y; Maizura, I and Rajinder, S (2012). Evaluation of MPOB oil palm germplasm (Elaeis guineensis) populations using EST- SSR. J. Oil Palm Res. Vol. 24: 1368-1377. 